\title{
Study on Allocation Efficiency of Agricultural Flood and Drought Disaster Reduction Project
}

\author{
LIU Jia \\ Department of Management Engineering, Engineering University of CAPF, Xi'an 710086, China \\ gege20010228@163.com
}

Keywords: agricultural flood and drought; disaster reduction project; allocation efficiency; data envelopment analysis

\begin{abstract}
Evaluating the allocation efficiency of agricultural flood and drought mitigation project is to investigate that whether the benefit brought by the project is effective from the economics angle of input-output. For the non-standardized weight distribution of the input-output indicators in the data envelopment analysis model, an improved data envelopment analysis model is proposed. Through constructing the decision-making unit and strengthening the weight constraint, the range of efficiency values is expanded and the weight of input-output indicators is standardized. In the end, this model is used to evaluate the allocation efficiency of agricultural flood and drought mitigation project of China’s 31 provinces, municipalities and autonomous regions.
\end{abstract}

\section{Introduction}

Natural disasters are the main factors influencing agricultural production in China, of which the flood and drought disaster (FDD) impacts the most seriously. In nearly 30 years, annual average crop area hit by FDD are 24.422 million hectares and 12.085 million hectares in mainland China, and annual average area covered by FDD are 12.608 million hectares and 6.632 million hectares. Crop losses caused by FDD are on rise year by year. The primary causes resulted in the serious FDD in our country are the relative shortage of water resources and uneven distribution of time and space. In addition, there are the causes of the geography and global climate change, etc. In order to defense FDD, most areas in China construct water conservancy projects to optimize the allocation of scarce water resources [1]. However, some water conservancy projects have not been repaired for many years, can the dangerous water conservancy projects complete the task of flood storage and detention? From the perspective of input and output, is it effective that the disaster reduction contribution brought from the new water conservancy projects? In order to solve these problems, the theory and method of the capital allocation efficiency were used to analyze the allocation efficiency of FDD projects of 31 provinces, municipalities and autonomous regions in China.

Data envelopment analysis (DEA) is a kind of mathematical programming method which was put forward on the basis of the concept of "relative efficiency" by well-known operations research experts A. Charnes and W. W. Cooper [2]. Since DEA model was established in 1978, it has been applied in the management science and system engineering, and has become an important tool in the evaluation technology.

As deterministic frontier model, DEA model has its unique advantages relative to the stochastic frontier model, include that the efficiency evaluation of multiple input and multiple output data can proceed, and the production function can be not established. Therefore, DEA model has been widely used $[3,4]$. But when using DEA model to evaluate the efficiency of more decision making units, if the weight is not scientific, the efficiency of more decision making units will not be sorted effectively. To allocate the weight scientifically, subjective weight method and the comprehensive weighting method were used, such as subjective preferences method [5], AHP method [6], Delphi method [7], principal component analysis, fuzzy comprehensive evaluation method [8], etc. These methods depend on the subjective preference of experts and decision makers. Because there is the personal bias in the process of using the subjective weight method inevitably, the decisions of experts and 
decision makers may be inconsistent, the same as the decisions of experts and experts. So the validity of the model evaluation results cannot be guaranteed.

In this paper, DEA model was improved, the decision making units of the most efficient and least efficient were constructed, weight constraint was strengthened, the range of objective weight of input and output index was regulated, distinction degree of decision making units was enhanced, influence of human factors was avoided.

\section{Model Design}

DEA Model. Assume that there are $n$ evaluation objects in DEA model, namely $n$ decision making units (DMU). Each evaluation object has $k$ inputs and $k$ outputs. For the $i$ th $D M U_{i}$, its input and output are represented by $x_{i}$ and $y_{i}$. Input matrix of $\mathrm{n} D M U s$ is $X$, and output matrix is $Y . X$ and $Y$ represent the data of input and output. The efficiency evaluation value of $i$ th $D M U_{i}$ is $u^{\prime} y_{i} / v^{\prime} x_{i}$, which $u$ is weight matrix of output indicators, $v$ is weight matrix of input indicators. To solve the optimal $u$ and $v$ is solving linear programming below:

$$
\left\{\begin{array}{l}
\max \left(u^{\prime} y_{i} / v^{\prime} x_{i}\right) \\
\text { st } \quad u^{\prime} y_{i} / v^{\prime} x_{i} \leqslant 1 \quad j=1,2, \cdots, n \\
\quad u \geqslant 0, \quad v \geqslant 0
\end{array}\right.
$$

Known from Formula (1), the efficiency value of $D M U$ is set less than or equal to 1 . So $u$ and $v$ have infinite solutions. To get effective solution, set $v^{\prime} x_{j}=1$ to constrain Formula 1 , that is to say Formula (1) is transformed into equivalent linear programming multiplier form (2).

$$
\begin{cases}\max \left(u^{\prime} y_{i}\right) & \\ \text { st } & u^{\prime} y_{i} / v^{\prime} x_{i} \leq 1 \quad j=1,2, \cdots, n \\ & v^{\prime} x_{j}=1 \\ & u \geq 0, \quad v \geq 0\end{cases}
$$

After Charnes-Cooper transformation, multiplier form of Formula (2) can be converted to linear programming dual form (3), namely the classic DEA model $\mathrm{C}^{2} \mathrm{R}$ :

$$
\left\{\begin{array}{l}
\min (\theta) \\
\text { st } \quad-y_{i}+Y \lambda \geq 0 \\
\quad \theta x_{i}-X \lambda \geq 0 \\
\lambda \geq 0
\end{array}\right.
$$

Where $\theta$ is a scalar, $\theta$ represents the efficiency score, and $0 \leq \theta \leq 1$. When $\theta=1, \theta$ represents the points on the frontier efficiency. $\lambda$ is a constant vector. There is less constraints in the linear programming binary form than the multiplier form, which may lead to set the unreasonable weight of input and output index.

Improvement of DEA Model. In view of less constraint of input and output vector weights, DEA model was improved in this paper. First of all, the most efficient $D M U$ and least $D M U$ are constructed. Secondly, through calculating the efficiency value $\theta=1$ of the most efficient $D M U$, weight vectors of many groups input and output index are determined. Thirdly, choose a group of weight vectors of input and output index and make the efficiency value $\theta \rightarrow 0$ of the least efficient $D M U$, namely the value of $\theta$ is the minimum. Thus, this set of weight vector is the input and output index weight vector of improved DEA model. The steps of model improving are as follows:

Step 1: construct the highest efficient and the lowest efficient DMUs

Construct the highest efficient $D M U_{\mathrm{n}+1}$ and the lowest efficient $D M U_{\mathrm{n}+2}$, input and output indicators of $D M U_{\mathrm{n}+1}$ are as follows:

$$
X_{n+1}=\left(x_{1, n+1}, x_{2, n+1}, \cdots x_{i, n+1} \cdots x_{k, n+1}\right)^{T}, Y_{n+1}=\left(y_{1, n+1}, y_{2, n+1}, \cdots x_{i, n+1} \cdots y_{m, n+1}\right)^{T}
$$

Input indicator and output indicator of the highest efficient $D M U_{n+1}$ are given the values of 
minimum of the input indicator and maximum of output indicators from the first $n$ DMUs, namely:

$$
x_{i, n+1}=\min \left(x_{i, 1}, x_{i, 2}, \cdots x_{k, n}\right), y_{i, n+1}=\max \left(y_{i, 1}, y_{i, 2}, \cdots y_{k, n}\right)
$$

Input indicator and output indicator of the lowest efficient $D M U_{n+2}$ are:

$$
X_{n+2}=\left(x_{1, n+2}, x_{2, n+2}, \cdots x_{i, n+1} \cdots x_{k, n+2}\right)^{T}, Y_{n+2}=\left(y_{1, n+2}, y_{2, n+2}, \cdots x_{i, n+2} \cdots y_{m, n+2}\right)^{T}
$$

Input indicator and output indicator of lowest efficient $D M U_{n+2}$ are given the values of minimum of the input indicator and maximum of output indicators from the first $n$ DMUs, namely:

$$
x_{i, n+2}=\max \left(x_{i, 1}, x_{i, 2}, \cdots x_{k, n}\right), \quad y_{i, n+2}=\min \left(y_{i, 1}, y_{i, 2}, \cdots y_{k, n}\right)
$$

Step 2: calculate weight vector of Input and output indicators

Evaluate original n DMUs and the highest efficient $D M U$ making use of DEA. Because $D M U_{n+1}$ is the highest efficient $D M U, \theta=1$, when $i=n+1$. Optimal weights $u *^{\prime}$ and $v *^{\prime}$ are obtained, and $u *^{\prime} y_{j} / v *^{\prime} x_{j}=1$.

$$
\begin{cases}\min _{n+1}(\theta)=1 \\ \text { st } & -y_{i}+Y \lambda \geq 0 \quad i=1,2, \cdots, n+1 \\ & \theta x_{i}-X \lambda \geq 0 \\ & u *^{\prime} y_{j} / v *^{\prime} x_{j}=1 \\ & \lambda \geq 0\end{cases}
$$

Step 3: solve commonality weight vector of input and output indicators

For $D M U_{n+2}$, exist:

$$
\left\{\begin{array}{l}
\min _{n+2}(\theta) \rightarrow 0 \\
s t \quad-y_{i}+Y \lambda \geq 0 \quad i=1,2, \cdots, n+2 \\
\\
\theta x_{i}-X \lambda \geq 0 \\
\\
u *^{\prime} y_{j} / v *^{\prime} x_{j}=1 \\
\left(u *^{\prime \prime}, v *^{\prime \prime}\right) \in\left(u *^{\prime}, v *^{\prime}\right) \\
\lambda \geq 0
\end{array}\right.
$$

Find only one weight vector $\left(u *^{\prime \prime}, v *^{\prime \prime}\right) \in\left(u *^{\prime}, v *^{\prime}\right)$ through formula (5), which makes $\theta \rightarrow 0$, when $i=n+2 . u *^{\prime \prime}$ and $v *^{\prime \prime}$ are the communal solution vector, then evaluate $n$ DUMs using formula (6).

$$
\left\{\begin{array}{l}
\min (\theta) \\
\text { st } \quad-y_{i}+Y \lambda \geq 0 \quad i=1,2, \cdots, n \\
\quad \theta x_{i}-X \lambda \geq 0 \\
\\
u *^{\prime} y_{j} / v *^{\prime} x_{j}=1 \\
\left(u *^{\prime \prime}, v *^{\prime \prime}\right) \in\left(u *^{\prime}, v *^{\prime}\right) \\
\lambda \geq 0
\end{array}\right.
$$

\section{Allocation Efficiency Evaluation of Agricultural FDD Mitigation Project}

Agricultural FDD mitigation projects include water conservancy disaster mitigation projects and ecological disaster reduction projects. Water conservancy disaster mitigation project consists of reservoirs, dikes, electromechanical irrigation and drainage pumping station, electromechanical well irrigation, and agricultural water pumps. Forests and wetlands include in ecological disaster reduction engineering. Because of various index of agricultural disaster reduction engineering, it is necessary to get rid of correlate index. Typical index method is used to filtrate the index of agricultural disaster reduction in this paper, and extract the main information of agricultural disaster reduction engineering, which makes the index independent but also covers the evaluation content. 
Filtrate Input Indicators Of Agricultural Disaster Reduction Projects. Typical index method assumes given $p$ indicators and $n$ set samples that can be expressed with matrix $X$, namely

$$
X=\left[\begin{array}{cccc}
x_{11} & x_{12} & \cdots & x_{1 p} \\
x_{21} & x_{22} & \cdots & x_{2 p} \\
\vdots & \vdots & \cdots & \vdots \\
x_{n 1} & x_{n 2} & \cdots & x_{n p}
\end{array}\right]
$$

Based on given matrix $X$, mean value $\bar{X}_{i}=\frac{1}{n} \sum_{k=1}^{n} x_{k i}(i=1,2, \cdots p)$, variance $S_{i i}=\frac{1}{n} \sum_{k=1}^{n}\left(x_{k i}-\bar{X}_{i}\right)^{2}$ $(i=1,2, \cdots p)$ and covariance $S_{i j}=\frac{1}{n} \sum_{k=1}^{n}\left(x_{k i}-\bar{X}_{i}\right)\left(x_{k j}-\bar{X}_{j}\right) \quad(i=1,2, \cdots p, j=1,2, \cdots p, i \neq j)$ can be calculated. $S_{i j}$ make up of matrix $S=\left(S_{i j}\right)_{p \times p}$ 。

Select typical indicators with simple correlation coefficient method. Assuming that there are $n$ indicators, respectively $a_{1}, a_{2}, \cdots, a_{n}$.

Step 1: Calculate correlation coefficient matrix $R$ between $n$ index using matrix $S$

$$
r_{i j}=\frac{s_{i j}}{\sqrt{s_{i i} s_{i j}}}(i, j=1,2, \cdots p) \quad R=\left[\begin{array}{cccc}
r_{11} & r_{12} & \cdots & r_{1 p} \\
r_{21} & r_{22} & \cdots & r_{2 p} \\
\vdots & \vdots & \cdots & \vdots \\
r_{p 1} & r_{p 2} & \cdots & r_{p p}
\end{array}\right]
$$

Step 2: Calculate the square correlation coefficient between each index and the remaining $n-1$ indicators

$$
\bar{r}_{i}^{2}=\frac{1}{n-1}\left(\sum_{j=1}^{n} r_{i j}^{2}-1\right)
$$

$\bar{r}_{i}^{2}$ reflects the correlation degree between $a_{i}$ and remaining $n-1$ indicators.

Step 3: If $\bar{r}_{k}^{2}=\max _{1 \leq i \leq n} \bar{r}_{i}^{2}, a_{k}$ can be chosen as typical indicator of $a_{1}, a_{2}, \cdots, a_{n}$. And so on, number of typical indicators is $n-2$ at most. If the correlation coefficient determinant value of the selected typical indicators is unequal to $0(|R| \neq 0)$, it will mean that the selected indicators are independent,

\begin{tabular}{|c|c|c|}
\hline Indicator & $\max _{1 \leq i \leq n} \bar{r}_{i}^{2}$ & Unit \\
\hline Reservoir capacity $\left(a_{1}\right)$ & $\max _{1 \leq i \leq 3} \bar{r}_{i}^{2}=\bar{r}_{1}^{2}=0.21$ & $\begin{array}{l}\text { a hundred million } \\
\text { cubic meters }\end{array}$ \\
\hline Electromechanical well irrigation $\left(a_{2}\right)$ & - & - \\
\hline Dike length $\left(a_{3}\right)$ & $\max _{1 \leq i \leq 7} \bar{r}_{i}^{2}=\bar{r}_{3}^{2}=0.76$ & $\mathrm{~km}$. \\
\hline Water pump ( $\left.a_{4}\right)$ & - & 一 \\
\hline $\begin{array}{l}\text { Installed capacity of Electrical irrigation } \\
\text { and drainage station }\left(a_{5}\right)\end{array}$ & $\max _{1 \leq i \leq 6} \bar{r}_{i}^{2}=\bar{r}_{5}^{2}=0.51$ & $10^{3}$ kilowatt \\
\hline Forest $\left(a_{6}\right)$ & $\max _{1 \leq i \leq 5} \bar{r}_{i}^{2}=\bar{r}_{6}^{2}=0.42$ & $10^{4}$ hectare \\
\hline Wetland $\left(a_{7}\right)$ & $\max _{1 \leq i \leq 4} \bar{r}_{i}^{2}=\bar{r}_{7}^{2}=0.36$ & $10^{3}$ hectare \\
\hline
\end{tabular}
and can cover evaluation content.

Table 1 Selected result of input indicators of agricultural FDD reduction projects

Table 1 is the result of filtrating the indicators of agricultural disaster reduction project making use of typical index selection method. By the value of $\bar{r}_{i}^{2}$, reservoirs, dikes, electromechanical irrigation and drainage pumping station, forest, wetland are confirmed as the input indicators of agricultural floods disaster reduction projects. 
The improvement of the disaster reduction project can increase the area of waterlogged and irrigation, and as a result, waterlogged area and effective irrigation area are selected as the output indicators of evaluating the disaster reduction project. Input and output index and unit are shown in table 2.

Since the values of correlation coefficient matrix of input and output index are $\left|R_{5 \times 5}\right|=0.031,\left|R_{2 \times 2}\right|=0.164$, input indexes and output indexes are not correlative.

Table 2 Input indexes and output indexes

\begin{tabular}{|c|c|c|c|}
\hline Sort & Index & Index introduction & Unit \\
\hline \multirow{5}{*}{$\begin{array}{l}\text { Input } \\
\text { indexes }\end{array}$} & Reservoir & $\begin{array}{l}\text { Reservoir can play a dual role by flood storage and } \\
\text { flood detention. Storage capacity is to measure. }\end{array}$ & $\begin{array}{l}\text { a hundred million } \\
\text { cubic meters }\end{array}$ \\
\hline & Dike & $\begin{array}{l}\text { Dike is the main measure to defend flood and protect } \\
\text { residents and industrial and agricultural production. } \\
\text { Dike length is to measure. }\end{array}$ & $\mathrm{km}$. \\
\hline & $\begin{array}{l}\text { Electrical } \\
\text { irrigation and } \\
\text { drainage }\end{array}$ & $\begin{array}{l}\text { Electrical irrigation and drainage uses dynamic } \\
\text { mechanical to drive pump and irrigate. Installed } \\
\text { capacity of mechanical and electrical station is to } \\
\text { measure. }\end{array}$ & $10^{3}$ kilowatt \\
\hline & Forest & $\begin{array}{l}\text { The forest can conserve water, reduce hazards of sand } \\
\text { storms, and reduce water loss and soil erosion, which } \\
\text { is of great significance for agricultural disaster } \\
\text { reduction. Forest covered area is to measure. }\end{array}$ & $10^{4}$ hectare \\
\hline & Wetland & $\begin{array}{l}\text { Wetlands play an important role on water } \\
\text { conservation, flood storage and controlling soil } \\
\text { erosion, which is important storage reservoir. Wetland } \\
\text { area is to measure. }\end{array}$ & $10^{3}$ hectare \\
\hline $\begin{array}{l}\text { Output } \\
\text { indexes }\end{array}$ & $\begin{array}{l}\text { Waterlogged } \\
\text { Irrigation }\end{array}$ & $\begin{array}{l}\text { Waterlogged area } \\
\text { Irrigation area }\end{array}$ & $\begin{array}{l}10^{3} \text { hectare } \\
10^{3} \text { hectare }\end{array}$ \\
\hline
\end{tabular}

Data Source. Data in this paper comes from the 2011 China statistical yearbook, the 2011 China agricultural yearbook and the 2011 China water conservancy yearbook. 31 provinces, autonomous regions and municipalities directly under the central government are selected as the sample.

Empirical Result And Analysis. Using DEA and improved DEA to evaluate the efficiency of agricultural disaster reduction projects of 31 provinces, municipalities and autonomous regions in China. The results are shown in table 3.

Table 3 Evaluation results and sorting of decision units

\begin{tabular}{cccc|cccc}
\hline District & DEA & $\begin{array}{c}\text { Improved } \\
\text { DEA }\end{array}$ & Ranking & District & DEA & $\begin{array}{c}\text { Improved } \\
\text { DEA }\end{array}$ & Ranking \\
\hline Sichuan & 1 & 0.657 & 1 & Shanghai & 1 & 0.428 & 17 \\
Fujian & 1 & 0.642 & 2 & Jiangxi & 1 & 0.427 & 18 \\
Chongqing & 1 & 0.614 & 3 & Gansu & 1 & 0.426 & 19 \\
Ningxia & 1 & 0.610 & 4 & Beijing & 1 & 0.326 & 20 \\
Heilongjiang & 1 & 0.580 & 5 & Henan & 1 & 0.325 & 21 \\
Hebei & 1 & 0.558 & 6 & Guizhou & 1 & 0.324 & 22 \\
Hainan & 1 & 0.543 & 7 & Zhejiang & 1 & 0.320 & 23 \\
Tianjin & 1 & 0.542 & 8 & Jilin & 1 & 0.318 & 24 \\
Jiangsu & 1 & 0.541 & 9 & Liaoning & 1 & 0.252 & 25 \\
Shandong & 1 & 0.441 & 10 & Guangdong & 0.950 & 0.224 & 26 \\
Shanxi & 1 & 0.439 & 11 & Guangxi & 0.939 & 0.220 & 27 \\
Neimenggu & 1 & 0.438 & 12 & Hubei & 0.896 & 0.199 & 28 \\
Xinjiang & 1 & 0.433 & 13 & Anhui & 0.862 & 0.189 & 29 \\
Shaanxi & 1 & 0.432 & 14 & Qinghai & 0.789 & 0.187 & 30 \\
Hunan & 1 & 0.431 & 15 & Yunnan & 0.731 & 0.142 & 31 \\
Tibet & 1 & 0.429 & 16 & & & & \\
\hline
\end{tabular}

In the results using DEA model, there are 25 provinces of which disaster reduction project efficiency values are equal to 1, and the efficiency values of other 6 provinces including Anhui, Jiangxi, Hubei, Guangdong, Guangxi and Yunnan are different. Therefore, DEA model cannot sort the disaster reduction project allocation efficiency of 25 provinces effectively. While, the disaster reduction project allocation efficiencies of every province by improved DEA are different totally. 
Through comparing the results, the disaster reduction projects allocation efficiency of decision units can be distinguished and sorted effectively. And that, the provinces which the disaster reduction project allocation efficiency is invalid by DEA are consistent with the provinces which the allocation efficiency is less effective, which illustrates the efficiency sorting result by improved DEA model is rational. From the efficiency values of two models, the values using DEA are between $0.731-1$, the difference value is 0.269 . The values using improved DEA are between $0.142-0.657$, the difference value is 0.515 . More efficiency difference expands the scope of decision units' efficiency value, enhance the comparability of decision units, and distinguish and sort the decision units effectively.

When determining weights of input and output index, DEA model is aimed to benefit to every decision unit, the weight constraint is broader. While, improved DEA model affirms the least efficient decision unit as the public weight vector, at the same time affirming the efficiency value of the highest decision unit is 1 . Determining weights methods of two models are different leads to the different efficiency values. In comparison, the weights by improved DEA model are more standard, which can make the evaluation results more reasonable and objective.

\section{References}

[1] Zheng RQ, Chen ZJ, Kang XL, et al. Discussion on Rural Water Conservancy Development Route from the Perspective of Agricultural Comprehensive Production Capacity [J]. Journal of Northwest A\&F University (Social Science Edition), 2013, 13(6): 31-36. (in Chinese)

[2] Charnes A., Cooper W.W., Rhodes E. Measuring the Efficiency of Decision Making Units [J]. European Journal of Operational Research, 1978, 2(6): 429-444.

[3] Asmild M., Parad J.C., Pastor J.T.. Centralized Resource Allocation BBC Models [J]. The International Journal of Productivity Analysis, 2004, 22(3): 143-161.

[4] Sufian F., Majid M.Z.A.. Bank Mergers Performance and the Determinants of Singaporean Banks Efficiency [J]. Gadjah Mada International Journal of Business, 2007, 9(1): 19-30.

[5] Zhang Y, Wang X J.Tender Evaluation Method for Engineering Projects Based on the Method of G1 and Modified DEA [J]. Science Research Management, 2012, 33(3): 136-141. (in Chinese)

[6] Yan HH, Cui JC. Multifactor Sequencing Method Based on AHP and DEA [J]. Journal of Systems Engineering, 2004, 19(5): 543-547. (in Chinese)

[7] Gregory B.. A Method for Assessing Highway Qualities to Integrate Values in Highway Planning [J]. Journal of Transport Geography, 2005(11): 271-283.

[8] Palaneeswaran E., Kumaraswamy M., Rahman M., et al. Curing Congenital Construction Industry Disorders through Relationally Integrated Supply Chains [J]. Building and Environment, 2003, (38): 571-582. 